Received: 13.10 .2020

Revised: 14.12 .2020

Accepted: 18.12 .2020

DOI: $10.17804 / 2410-9908.2020 .6 .048-053$

\title{
PRODUCTION OF PURE NICKEL ALLOYS DOPED WITH SULFUR AND PHOSPHORUS
}

\author{
S. E. Danilov* and V. L. Arbuzov \\ M.N. Miheev Institute of Metal Physics, Ural Branch of the Russian Academy of Sciences, \\ 18 S. Kovalevskoy St., Ekaterinburg, 620137, Russian Federation \\ a) (iD https://orcid.org/0000-0001-9815-8196 ه danilov@imp.uran.ru; \\ b) (iD https://orcid.org/0000-0003-0334-7459 \\ *Corresponding author. E-mail: danilov@imp.uran.ru \\ Address for correspondence: ul. S. Kovalevskoy, 18, Ekaterinburg, 620108, Russian Federation
}

\begin{abstract}
A procedure for alloying nickel with sulfur and phosphorus by diffusion and homogenizing annealing is described using the example of pure nickel (RRR at 600). A scheme of the installation for alloying from the gas phase is described. The possibility of uniform alloying with sulfur and phosphorus of samples and material in the form of plates or foils with a thickness of $0.2 \mathrm{~mm}$ or thinner at a concentration ranging between 0.001 and 0.08) at. \% is shown. Diffusion annealing is carried out after heating and pumping out in a high vacuum and without contamination, in a quartz volume containing sulfur or phosphorus vapors at a temperature of 1100 to $1200{ }^{\circ} \mathrm{C}$. By choosing the ratio of the masses of the alloyed material and the corresponding filling of sulfur or phosphorus, it is possible to predict in advance the resulting concentration of impurities with a sufficient time of annealing. The impurity concentration is uniform in volume within ten percent. Modeling and control annealings with the measurement of the residual resistivity of the control samples allows you to evaluate the results obtained.
\end{abstract}

Keywords: alloying, sulfur, phosphorus, nickel, diffusion, homogenization.

\section{Acknowledgment}

The work was carried out within the framework of the state assignment from the Ministry of Education and Science of Russia, theme "Function" No. 0388-2019-0004, and partially supported by the Russian Foundation for Basic Research, project No. 18-02-00270.

\section{References}

1. Van Wazer J.R. Phosphorus and its Compounds, Interscience Publishers, New York, N. Y., vol. I, 1958, p. 283.

2. Arbuzov V.L., Vladimirov A.B., Danilov S.E., Klotsman S.M., Trakhtenberg I.Sh. Diffusion, Solubility, and Residual Electrical Resistance in Nickel-Sulfur Alloys. Fiz. Met. Metalloved., 1980, vol. 49, no. 2, pp. 356-362. (In Russian).

3. Bokshtein B.S. Diffusion in Metals. Moscow, Metallurgiya Publ., 1978, 248 p. (In Russian).

4. Kablov D.E., Sidorov V.V., Puchkov Yu.A. Diffusion behavior features of impurities and microalloying additives in nickel and single crystal superalloys. Aviatsionnye Materialy i Tekhnologii, 2016, no. 1 (40). DOI: 10.18577/2071-9140-2016-0-1-24-31. (In Russian).

5. Titov K.V. Chislennye metody resheniya zadach diffuzii [Numerical Methods for Solving the Diffusion Problems: study guide]. Moscow, Izd-vo MGTU im. N.E. Baumana Publ., 2009, 48 p. (In Russian). 
6. Tikhonov A.N., Samarskiy A.A. Uravneniya matematicheskoy fiziki [The Equations of Mathematical Physics]. Moscow, Izd-vo MGU, 2004. (In Russian). 
Подана в журнал: 13.10 .2020

УДК 669-1:53.08

DOI: $10.17804 / 2410-9908.2020 .6 .048-053$

\title{
ПОЛУЧЕНИЕ ЧИСТЫХ СПЛАВОВ НИКЕЛЯ, ЛЕГИРОВАННЫХ СЕРОЙ И ФОСФОРОМ
}

\author{
С. Е. Данилов ${ }^{*}$, В. Л. Арбузов \\ Институт физики металлов, им. М.Н. Михеева УрО РАН, \\ 18, ул. Софьи Ковалевской, Екатеринбург, 620108, Российская Федераичя \\ a) (iD https://orcid.org/0000-0001-9815-8196 ه danilov@imp.uran.ru; \\ б) (iD https://orcid.org/0000-0003-0334-7459
}

\author{
*Ответственный автор. Электронная почта: danilov@imp.uran.ru \\ Адрес для переписки: ул. С. Ковалевской, 18, 620108, Екатеринбург, Российская Федерация
}

Описана методика легирования никеля серой и фосфором путем диффузионных и гомогенизирующих отжигов на примере чистого никеля с RRR (Residual Resistivity Ratio) на уровне 600. Описана схема установки для легирования из газовой фазы. Показана возможность равномерного легирования серой и фосфором образцов и материала в виде пластин или фольг толщиной на уровне 0,2 мм или тоньше, в диапазоне концентраций $(0,001-0,08)$ ат. \%.

Диффузионный отжиг проводится после прогрева и откачки в высоком вакууме и закупорки, в кварцевом объеме, содержащем пары серы или фосфора при температуре $1100-1200{ }^{\circ} \mathrm{C}$. За счет выбора соотношения масс легируемого материала и соответствующей закладки серы или фосфора можно заранее прогнозировать получаемую концентрацию примеси при достаточном времени легирующего отжига. Концентрация примеси равномерна по объему в пределах десятка процентов. Проведение моделирующих и контрольных отжигов с измерением остаточного электросопротивления контрольных образцов позволяет оценивать получаемые результаты.

Ключевые слова: легирование, сера, фосфор, никель, диффузия, гомогенизация.

\section{1. Введение}

При проведении исследований, связанных с определением роли примесей в процессе различных внешних воздействий (облучение, деформация, термические процедуры и др.) часто возникает необходимость получения наборов образцов с известной концентрацией легирующей примеси при ее варьировании. При таком легировании, необходимо избежать или уменьшить до минимума проникновение в исследуемые образцы других примесей $[1,2]$. В работе описана методика приготовления сплавов типа Ni-S или Ni-P из чистого никеля (RRR на уровне 600) в виде фольг или тонких монокристаллических пластин толщиной 0,2 мм в диапазоне концентраций 0,001-0,08 ат. \% путем диффузионных отжигов.

\section{2. Материал и методика}

Установка для диффузионного насыщения представляет собой кварцевую запаянную трубу 1 диаметром около 35-37 мм, присоединенную к высоковакуумной безмасляной откачной системе Эра-250, с магниторазрядным насосом Норд-250 (рисунок). 


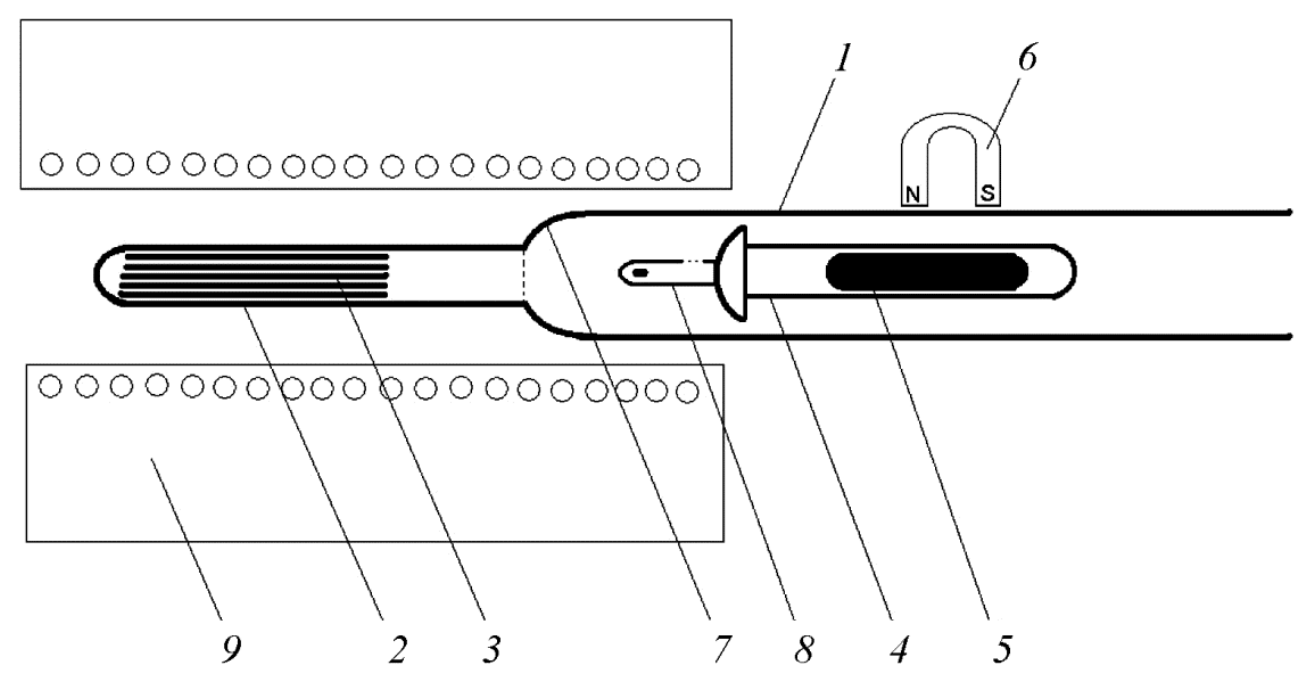

Схема установки для диффузионного легирования (пояснения в тексте)

В случае отсутствия существенного газовыделения насос может создать в трубе вакуум на уровне $10^{-6}$ мм. рт. ст. На конце трубы приварен кварцевый стакан 2 с внутренним диаметром около 15 мм. Стопка пластин из насыщаемого серой или фосфором материала 3 расположена в этом стакане. Между пластинами имеется зазор около 0,3 мм для свободного прохождения газа. Внутри трубы имеется перемещаемый шток 4, изготовленный из кварца. Шток имеет запаянную трубу, содержащую железный свободно расположенный цилиндр 5. Цилиндр служит для перемещения штока вдоль тубы с помощью расположенного снаружи магнита 6. Шток имеет утолщение на конце, прижимаемом к основанию стакана. Это утолщение имеет притертую шаровую поверхность, являющуюся ответной к притертой шаровой внутренней поверхности участка перехода 7 с кварцевой трубы на кварцевый стакан. На конце штока, оказывающемся внутри стакана приварен кварцевый выступ 8 , изготовленный из тонкой кварцевой трубки, запаянной и имеющей боковое отверстие. В этот выступ помещается легирующее вещество (сера или фосфор). Снаружи стакана и трубы расположена снимаемая печь 9, позволяющая поддерживать температуру, необходимую для диффузионного насыщения. Остаточное электросопротивление контрольных образцов, насыщаемых вместе с пластинами, измеряли на автоматизированном комплексе при 4,2 К с точностью $0,05 \%$ и чувствительностью $5 \cdot 10^{-12}$ Ом.см.

\section{3. Результаты и обсуждение}

При проведении насыщения вначале шток отодвигался внешним магнитом на расстояние, достаточное для того, чтобы он имел комнатную температуру. В таком положении проводился обезгаживающий отжиг легируемого материала и кварцевого стакана при температуре около $900{ }^{\circ} \mathrm{C}$ в течение часа. После снятия печи и охлаждения трубы со стаканом до комнатной температуры шток с помощью магнита вдвигался и запирал притертым утолщением стакан с насыщаемым материалом. При этом кварцевый выступ 8, содержащий легирующее вещество оказывался внутри объема стакана. После этого печь вновь надевалась и производился диффузионный отжиг при $1150-1200{ }^{\circ} \mathrm{C}$. При этом легирующее вещество испарялось и происходило заполнение стакана парами этого вещества. Поверхность пластин легируемого материала абсорбировала примесь и становилась диффузионным источником для проникновения примеси вглубь пластин. Решение диффузионной задачи по проникновению примеси с обеих сторон в плоскую пластину [2-6] позволило оценить время (30-40 ч), необходимое для равномерного насыщения объема с неоднородностью по толщине на уровне 10 \%. При этих температурах растворимость примесей в никеле выше 1000 ppm. Масса примеси и насыщаемого 
материала предварительно определялась взвешиванием. Это позволило провести расчет получаемой концентрации в предположении, что примесь не покидает объем стакана и полностью адсорбируется поверхностью пластин. При проведении диффузионных отжигов количество заложенной в выступ примеси не должно при оценках концентрации в насыщаемом материале превышать уровень растворимости примеси при температуре диффузионного отжига. После окончания диффузионного отжига печь снималась и проводилась закалка достигнутого состояния путем охлаждения стакана в сосуде с водой комнатной температуры с целью сохранить примесь в твердом растворе и не дать произойти распаду твердого раствора. Возможное проникновение примеси из стакана в трубу можно обнаружить по росту тока насоса. Этого в диффузионных насыщениях не было обнаружено. Концентрацию серы и фосфора в никеле после насыщения определяли из измерений электросопротивления с использованием значения вклада серы в остаточное электросопротивление никеля $\rho_{\mathrm{s}}=0,68 \mathrm{HOM} \mathrm{cm} / \mathrm{at} . \mathrm{ppm}$ [2] и вклада фосфора ориентировочно (по оценкам) 0,5 нОм см/at. ppm. В проведенных экспериментах по насыщению проводилось сравнение рассчитанной концентрации серы и фосфора исходя из соотношения масс с концентрацией, измеренной с помощью остаточного электросопротивления. Совпадение в пределах 6-8 \% можно считать дополнительным обоснованием чистоты эксперимента.

Давление насыщенных паров серы при комнатной температуре $2,8 \cdot 10^{-6}$ мм. рт. ст, давление насыщенных паров фосфора по теоретическим оценкам $1,910^{-8}$ мм. рт. ст. Таким образом, помещение легирующего вещества в выступ на штоке не приводит к ухудшению вакуума при обезгаживающем отжиге. Повышение температуры печи, произведенное после вдвигания штока, при диффузионном отжиге приводило к быстрому переходу легирующего вещества в газообразное состояние.

Для проверки чистоты эксперимента проводились холостые отжиги, включающие все процедуры, кроме закладки примеси в кварцевый выступ. Отжиг чистого никеля с отношением сопротивлений RRR на уровне 1000 дал величину RRR около 600, что говорит об отсутствии загрязнений на уровне 10 ppm.

\section{4. Заключение}

Описана схема установки для легирования из газовой фазы и методика легирования серой и фосфором путем диффузионных и гомогенизирующих отжигов на примере чистого никеля c RRR на уровне 600. Показана возможность равномерного легирования серой и фосфором образцов и материала в виде пластин или фольг толщиной на уровне 0,2 мм или тоньше, в диапазоне концентраций - $(0,001-0,08)$ ат. \% .

\section{Благодарность}

Работа выполнена в рамках государственного задания МИНОБРНАУКИ России (тема «Функиия» № 0388-2019-0004) при частичной поддержке РФФИ (проект № 18-02-00270).

\section{Литература}

1. Везер Ван Джон Р. Фосфор и его соединения : в 2 т. Т. 1 / пер. с англ. под ред. А. И. Шерешевского. - Москва : Изд-во иностранной литературы, 1962.

2. Диффузия, растворимость и остаточное электросопротивление серы в никеле / В. Л. Арбузов, А. Б. Владимиров, С. Е. Данилов, С. М. Клоцман, И. Ш. Трахтенберг // ФММ. - 1980. - Т. 49, № 2. - С. 356-362.

3. Бокштейн Б. С. Диффузия в металлах. - М. : Металлургия, 1978. - 248 с.

4. Каблов Д. Е., Сидоров В. В., Пучков Ю. А. Особенности диффузионного поведения примесей и рафинирующих добавок в никель и монокристаллы жаропрочных спла- 
вов // Авиац. материалы и технологии. - 2016. - № 1 (40). - DOI: 10/18577/ 2071-91402016-1-1-24-31.

5. Титов К. В. Численные методы решения задач диффузии : метод. указания к компьютерному практикуму по курсу «Уравнения математической физики». - М. : Изд-во МГТУ им. Н. Э. Баумана, 2009. - 48 с.

6. Тихонов А. Н., Самарский А. А. Уравнения математической физики. - М. : Изд. МГУ, 2004. 